See discussions, stats, and author profiles for this publication at: https://www.researchgate.net/publication/264782543

\title{
History of Birth Complications, Having Chronic Diseases and Children's Intelligence Quotient (IQ) at Age 7-8 Years Old in Baghdad City, Iraq
}

Article in International Journal of Maternal and Child Health · August 2014

DOI: $10.12966 /$ ijmch.08.02.2014

CITATIONS

0

5 authors, including:

Hasanain Faisal Ghazi

Al-Bayan University

182 PUBLICATIONS 511 CITATIONS

SEE PROFILE

Mohammed A. Abdalqader

Management and Science University

62 PUBLICATIONS 130 CITATIONS

SEE PROFILE

Some of the authors of this publication are also working on these related projects:

USAGE OF VITAMIN D SUPPLEMENTS AMONG ADULTS IN THE ERA OF COVID19 IN BAGHDAD CITY View project

IAMRS members Participation and certificates View project
READS

194

Zaleha md isa

Universiti Kebangsaan Malaysia

115 PUBLICATIONS 753 CITATIONS

SEE PROFILE

Dr. Tiba Nezar Hasan

Al-Turath University

34 PUBLICATIONS 72 CITATIONS

SEE PROFILE 


\title{
History of Birth Complications, Having Chronic Diseases and Children's Intelligence Quotient (IQ) at Age 7-8 Years Old in Baghdad City, Iraq
}

\author{
Hasanain Faisal Ghazi ${ }^{1, *}$, Zaleha Md. Isa ${ }^{1}$, Mohammed A. AbdalQader ${ }^{1}$, Tiba Nezar Hasan ${ }^{1}$ \& Namaitijiang \\ Maimaiti $^{2}$ \\ ${ }^{1}$ Department of Community Health, Universiti Kebangsaan Malaysia Medical Centre. Kuala Lumpur, Malaysia \\ ${ }^{2}$ United Nations University, International Institute for Global Health. Kuala Lumpur, Malaysia \\ *Corresponding author (Email: dr.hasanainhabasha@gmail.com)
}

\begin{abstract}
History of birth complications may affect cognitive development of children later in life. The main objective of this study was to determine the level of IQ and to assess its relationship with birth complications history and chronic diseases. A cross-sectional study was done in Baghdad city among 450 primary school children aged 7 to 8 years old. Translated questionnaires were distributed to mothers to answer, also Raven IQ tool was used to obtain children IQ level. A total of $22.2 \%$ children have low IQ score. The prevalence of birth complications history was $20.9 \%$. There was a significant association between birth complications history, having chronic diseases and parents working status with child's IQ status ( $\mathrm{p}=0.001, \mathrm{p}=0.041$ and $\mathrm{p}<0.001)$ respectively. After adjusting for confounders, history of birth complications remain a strong factor affecting children IQ status at age 7-8 years old in Baghdad city, Iraq. As a conclusion, having a history of birth complications during child delivery may affect IQ level later in life.
\end{abstract}

Keywords - Birth complications, Chronic diseases, Baghdad city, Iraq, Children

\section{Introduction}

Intelligence quotient (IQ), a quantitative measure of intelligence, was once thought to be a definitive way to measure cognitive capability within a specified range. Children's IQ development is a complicated process involving the environment where the child live, the food being consumed and also genetics inherited from parents.

Birth complications are defined as any difficulties or problems that occurred after the onset of labour. Some complications are potentially life-threatening, especially if they impaired the baby's oxygen supply. According to some studies, maternal complication accounted for $9-10 \%$ of all pregnant women or about 14 million women per year suffer from acute maternal complications (Hogan et al. 2010; Fillipe et al. 2006).

Investigations into the association between birth complications and low intelligence have been inconclusive. Many studies that use markers of asphyxia conclude that below-normal intelligence does not occur as a consequence of prenatal brain injury in the absence of cerebral palsy (Korkman et al. 1994; Paneth \& Starh 1983; Viggedal et al. 2002). On the other hand, in a large prospective study, risk factors for asphyxia were associated with difference in IQ at the age of 7 years old. Whereas one study found that the level of initial arterial acidosis was inversely related to IQ at early school age (Stevens et al. 1999).

Mariëlle van Handel et al. (2007) in their review about long-term cognitive and behavioral consequences of neonatal encephalopathy following perinatal asphyxia concluded that children with severe neonatal encephalopathy appeared to be impaired in every cognitive domain. They are less intelligent and perform worse at school at neuropsychological tests than both healthy controls and children with mild or moderate neonatal encephalopathy.

Chronic non-communicable diseases previously were exclusive to older adults, but their trend nowadays among children is on the rise. According to a study done by Antônio A Silva et al. in 2011 among Brazilian chidren, the prevalence of hypertension in Ribeirão Preto area was $10.9 \%$. They concluded that some non-communicable diseases were highly prevalent, especially in the more developed cities. Studies suggested that children with type 1 diabetes may be at risk of cognitive deficits, especially those diagnosed at earlier ages, those with lower socioeconomic status, and boys (Wysocki et al. 2003).

Moonie et al. (2008) concluded that children with asthma experienced more absenteeism from school compared to their 
no asthma peers. Excessive absenteeism is related to lower student grades, psychological, social, and educational adjustment.

The objective of this study was to determine the level of intelligence quotient (IQ) and to assess its relationship with birth complications history and chronic diseases among 7-8 years old school children in Baghdad city, Iraq.

\section{Materials \& Methods}

A cross- sectional study was carried out in Baghdad city Iraq among 450 primary school children aged 7-8 years old in 2011. The children were chosen from 4 primary schools representing different socio-economic status of people living in Baghdad City. The chosen schools were selected by simple random sampling.

Translated questionnaires were used in this study. Back-to-back translation was done to ensure the validity of the questions, and a pre-test was carried out. The questionnaires consist of 2 parts, socio-demographic data namely children's gender, parents educational level and working status. The second part consists of questions regarding history of birth complications during child delivery and also if the child suffer from any chronic non-communicable diseases. The questionnaires were self-administered to children's mothers during the monthly meeting at school.

Raven's Colored Progressive Matrices was used in this study to obtain children's IQ. It consists of 36 items in three sets of 12: A, AB and B. It is a cultural free intelligence tool to overcome the effect of translation from other languages to Arabic language. It is an internationally standardized tool and has been used before among Iraqi children (Raven et al. 1998). It was administered to the children by well-trained co-researchers using one-to-one technique.

Data was analyzed using SPSS version 21. Chi-square test was used for categorical data, and binary logistic regression was used in multivariable analysis.

This study was approved by the Research and Ethics Committee of Universiti Kebangsaan Malaysia Medical Centre with code number FF-180-2011. This study was also approved by the Iraqi Ministry of Education. Consent form from the parents was taken.

\section{Results}

Regarding IQ level, $22.2 \%$ of children have low IQ compared to $77.8 \%$ having high IQ score as shown in Table1. The prevalence of birth complication history was $20.9 \%$, and the most common complication was difficult birth $(85.1 \%)$ followed by birth asphyxia (8.5\%). Regarding chronic diseases, only $8.0 \%$ suffer from them with majority suffering from asthma (37.8\%) and followed by heart diseases $(16.3 \%)$. A total of $35.6 \%$ reported taking extra learning other than school hours and the most common source was either mother or father at home.

There was no difference between male and female in term of IQ score $(p=0.378)$ although the high IQ rate was higher among male compared to female. Mother and father educational level was not associated with child's IQ but working status was significantly associated with children's IQ $(\mathrm{p}<0.001)$ as shown in Table 2.

There was an association between having birth complications history and child's IQ $(p=0.001)$ in which children with birth complications history have 2.2 times more risk of having low IQ compared to those with no such history. Having chronic diseases were significantly associated with child's IQ ( $\mathrm{p}=0.042)$ as shown in Table 3.

Table 4 represents multiple logistic regression analysis. After adjusting for gender, mother's education and father's education, the history of birth complications, chronic diseases and parents working status still appear to be the most important factors influencing child IQ at age 7-8 years old in Baghdad city, Iraq.

\section{Discussion}

The main finding of our study is that having history of birth complications during delivery may affect children cognitive development in the future. Having chronic noncommunicable diseases was also significantly associated with child's IQ status.

The limitations of our study include the cross-sectional design which measures prevalence at a limited time in specific population, and the recall bias of the mothers especially regarding the history of birth complications. On the other hand, the strength of this study is the large sample size, and the fact that the children came from four different areas in Baghdad, providing information about conditions for people of different socioeconomic status and using international standardized tool in IQ measurements.

Many previous studies examined the consequences of either preterm or very preterm birth and they demonstrated that preterm delivery is associated with a number of long-term sequelae, including lower intelligence quotient (IQ) (Kerr-Wilson et al. 2011) and higher risk of specific impairments, including motor, behavioural, and language (De Kieviet et al.2009; Johnson 2007; Barre et al. 2010).

Some other studies explored the relationship between IQ, school performance and week of gestation. It was concluded that week of gestation demonstrated a dose-response relationship, in which risk of low IQ and poor school performance tend to reduce as mothers approaching to 40 weeks of gestation (Eide et al. 2007; Lagerstrom et al. 2001; Yang et al. 2010; Kirkegaard et al. 2006).

In a cohort study done by Mackay et al. (2012) regarding obstetric factors and different causes of special educational need, they concluded that "strong, consistent, and dose-dependent associations for sensory impairments, physical or motor disabilities, and intellectual disabilities, 
suggesting that obstetric factors may be causal and changes in obstetric practice and improvements in obstetric outcome could potentially have a significant impact on these conditions".

Children who are suffering from chronic illness may not show their abilities due to stay in hospitals, overprotection by parents or other factors (Pinquart \& Teubert 2012). The possible reason why sick children perform poorer than normal colleagues is first repeated school absence may affect and restrict academic success (Madan-Swain et al. 2004). In addition, prolonged stays in hospital and frequent doctor's visits may also affect child performance and finally pain and fatigue limit physical function (Garralda \& Rangel 2004).

\section{Conclusion}

History of birth complications during delivery can affect children's IQ later in life. Having chronic diseases was also associated with child's IQ status.

\section{Recommendations}

The Ministry of Health and other relevant ministries should try various methods to disseminate knowledge on birth complication happening during delivery to members of the community, for example through the media, workshops etc. More precautions should therefore be taken to avoid any trauma or injury to the child during delivery, and workshops should be given to health specialists and workers about the consequences of such trauma.

\section{Acknowledgement}

This study was funded by the Universiti Kebangsaan Malaysia Medical Centre Fundamental Research Grant, Code Number FF-180-2011 without which the study would not have been possible.

\section{Competing interests}

The authors declare that they have no competing interests.

\section{References}

Barre, N., Morgan, A., Lex, W. D., \& Peter, J. A. (2010) Language abilities in children who were very preterm and/or very low birth weight: A meta-analysis. J Pediatr 158,766-774

De Kieviet, J. F., Piek, J. P., Aarnoudse-Moens, C. S., \& Oosterlaan, J. (2009) Motor development in very preterm and very low birth weight children from birth to adolescence: A meta-analysis. JAMA; 302(20), 2235-2242.

Eide, M. G., Oyen, N., Skjaerven, R., Bjerkedal, T. (2007) Associations of birth size, gestational age, and adult size with intellectual performance:
Evidence from a cohort of Norwegian men. Pediatr Res; 62, 636-42. 21

Fillipi, V., Ronsmans, C., Campbell, O. M., Graham, W. J., Mills, A., Borghi, J., et al. (2006) Maternal health in poor countries: the broader context and a call for action. Lancet; 368, 1535-1541.

Garralda, E., \& Rangel, L. (2004). Impairment and coping in children and adolescents with chronic fatigue syndrome: A comparative study with other paediatric disorders. Journal of Child Psychology and Psychiatry; $45,543-552$.

Hogan, M. C., et al. (2010). Maternal mortality for 181 countries, 1980-2008: a systematic analysis of progress towards Millennium Development Goal 5. Lancet; 375, 1609-1623.

Johnson, S. (2007). Cognitive and behavioural outcomes following very preterm birth. Semin Fetal Neonatal Med; 12(5), 363-373.

Kerr-Wilson, C. O., Mackay, D. F., Smith, G. C. S., \& Pell, J. P. (2011). Meta-analysis of the association between preterm delivery and intelligence. $J$ Public Health; in press

Kirkegaard, I., Obel, C., Hedegaard, M., \& Henriksen, T. B. (2006) Gesational age and birth weight in relation to school performace of 10-year-old children: A follow-up study of children born after 32 completed weeks. Pediatrics; 118, 1600-1606.

Korkman, M., Hilakivi-Clarke, L. A., Autti-Ramo, I. (1994). Cognitive impairments at two years of age after prenatal alcohol exposure or perinatal asphyxia. Neuropediatrics, 25, 101-105.

Lagerstrom, M., Bremme, K., Eneroth, P., \& Magnusson, D. (2001) School performance and IQ-test scores at age 13 as related to birth weight and gestational age. Scand J Psychol; 32, 316-324.

Mackay, D., Smith, G., Dobbie, R., Cooper, S., Pell, J. (2012). Obstetric factors and different causes of special educational need: retrospective cohort study of 407503 school children. BJOG; 120, 297-308.

Madan-Swain, A., Katz, E. R., \& LaGory, J. (2004). School and social reintegration after a serious illness or injury. Handbook of Pediatric Psychology in School Settings (pp. 637-655). In R. T. Brown (Ed.).

Mariëlle, V. H., Hanna, S., Linda, S., \& Marian, J. J. (2007). Long-term cognitive and behavioral consequences of neonatal encephalopathy following perinatal asphyxia: a review. European Journal of Pediatric ;166, 645-654.

Moonie, S., Sterling, D., Figgs, L., \& Castro, M. (2008). The Relationship between School Absence, Academic Performance, and Asthma Status. Journal of School Health; 78, 140-148.

Paneth, N., Stark, R. I. (1983). Cerebral palsy and mental retardation in relation to indicators of perinatal asphyxia. American Journal Obstet Gynecol 1983;147, 960-966.

Pinquart, M., \& Teubert, D. (2012). Academic, Physical, and Social Functioning of Children and Adolescents with Chronic Physical Illness: A Meta-analysis. Journal of Pediatric Psychology; 37(4), 376-389.

Raven, J., Raven, J. C., \& Raven, J. H. (1998). Raven Coloured Progressive Matrices Manual. Harcourt Assessment. San Antonio. Texas. USA.

Silva, A. A., Barbieri, M. A., Cardoso, V. C., Batista, R. F., Simões, V. M., Vianna, E. O., Gutierrez, M. R., Figueiredo, M. L., Silva, N. A.,Pereira, T. S., Rodriguez, J. D., Loureiro, S. R., Ribeiro, V. S., Bettiol, H. (2011). Prevalence of non-communicable diseases in Brazilian children: follow-up at school age of two Brazilian birth cohorts of the 1990's.BMC Public Health, 11,486.

Stevens, C. P., Raz, S., Sander, C. J. (1999). Peripartum hypoxic risk and cognitive outcome: a study of term and preterm birth children at early school age. Neuropsychology; 13, 598-608.

Viggedal, G., Lundälv, E., Carlsson, G., Kjellmer, I. (2002). Follow-up into young adulthood after cardiopulmonary resuscitation in term and near-term newborn infants. II. Neuropsychological consequences. Acta Paediatrica; 91(11), 1218-1226.

Wysocki, T., Harris, A., Mauras, N., Fox, L., Taylor, A., Jackson, S., \& White, N. H. (2003). Absence of Adverse Effects of Severe Hypoglycemia on Cognitive Function in School-Aged Children with Diabetes Over 18 Months. Diabetes Care; 26, 110-1105.

Yang, S., Platt, R. W., Kramer, M. S. (2010). Variation in child cognitive ability by week of gestation among health term births. Am J Epidemiol; 171, 399-406. 
Table 1. History of birth complications, chronic diseases and IQ level of the children

\begin{tabular}{|l|c|c|}
\hline \multicolumn{1}{|c|}{ Variables } & N & \% \\
\hline History of birth complications & & 20.9 \\
\hline Yes & 94 & 79.1 \\
\hline No & 356 & \\
\hline Having chronic diseases & & 8.0 \\
\hline Yes & 36 & 92.0 \\
\hline No & 414 & \\
\hline Intelligence Quotient (IQ) & & 22.2 \\
\hline Low & 100 & 77.8 \\
\hline High & 350 & \\
\hline
\end{tabular}

Table 2. Relationship between socio-demographic characteristics and Intelligence Quotient (IQ) of the children

\begin{tabular}{|l|c|c|c|c|c|}
\hline & Low IQ & High IQ & P value $^{\mathbf{a}}$ & POR & 95\% CI \\
\hline & $\mathbf{N}(\boldsymbol{\%})$ & $\mathbf{N}(\boldsymbol{\%})$ & & & \\
\hline Sex & & & & & \\
\hline Male & $97(42.0)$ & $134(58.0)$ & 0.378 & 1.182 & $0.815-1.716$ \\
\hline Female & $101(46.1)$ & $118(53.9)$ & & 1.000 & \\
\hline Family Working Status & & & & & \\
\hline Both spouse work & $54(34.2)$ & $104(65.8)$ & $<\mathbf{0 . 0 0 1}$ & 1.000 & \\
\hline One spouse work & $120(46.3)$ & $139(53.7)$ & $<\mathbf{0 . 0 0 1}$ & 1.663 & $1.104-2.504$ \\
\hline Neither working & $24(72.2)$ & $9(27.3)$ & $\mathbf{0 . 0 1 5}$ & 5.136 & $2.231-11.821$ \\
\hline Mother Education & & & & & \\
\hline Low & $43(50.6)$ & $42(49.4)$ & 0.171 & 0.718 & $0.447-1.154$ \\
\hline High & $153(42.2)$ & $208(57.6)$ & & 1.000 & \\
\hline Father Education & & & & & \\
\hline Low & $24(43.6)$ & $31(56.4)$ & 0.813 & 0.933 & $0.526-1.654$ \\
\hline High & $151(41.9)$ & $209(58.1)$ & & 1.000 & \\
\hline
\end{tabular}

${ }^{a}$ Pearson Chi Square test was performed; level of significant is at $\mathrm{p}<0.05, \mathrm{POR}=$ prevalence odds ratio, $\mathrm{CI}=$ confidence interval

Table 3. Relationship between birth complications history, chronic diseases with Intelligence Quotient (IQ) of the children

\begin{tabular}{|l|c|c|c|c|c|}
\hline & Low IQ & High IQ & P value $^{\mathbf{a}}$ & POR & 95\% CI \\
\hline & $\mathbf{N}(\%)$ & $\mathbf{N}(\%)$ & & & \\
\hline Birth complications History & & & & & \\
\hline Yes & $56(59.6)$ & $38(40.4)$ & $\mathbf{0 . 0 0 1}$ & 2.221 & $1.397-3.530$ \\
\hline No & $142(39.9)$ & $214(60.1)$ & & 1.000 & \\
\hline Chronic Diseases & & & & & \\
\hline Yes & $10(27.8)$ & $26(72.2)$ & $\mathbf{0 . 0 4 1}$ & 0.462 & $0.217-0.963$ \\
\hline No & $188(45.4)$ & $226(54.6)$ & & 1.000 & \\
\hline Extra Learning & & & & & \\
\hline Yes & $59(36.9)$ & $101(63.1)$ & $\mathbf{0 . 0 2 4}$ & 0.635 & $0.427-0.942$ \\
\hline No & $139(47.9)$ & $151(52.1)$ & & 1.000 & \\
\hline
\end{tabular}

${ }^{a}$ Pearson Chi Square test was performed; level of significant is at $\mathrm{p}<0.05, \mathrm{POR}=$ prevalence odds ratio, $\mathrm{CI}=$ confidence interval

Table 4. Multiple logistic regression analysis to predict low IQ among 7-8 years old school children in Baghdad city, Iraq

\begin{tabular}{|l|l|l|l|l|l|}
\hline Variable & $\mathbf{B}$ & Wald & P value & Adj OR $^{\mathbf{a}}$ & $\mathbf{9 5 \%}$ CI \\
\hline Sex & 0.017 & 0.007 & 0.993 & 1.017 & $0.686-1.507$ \\
\hline Chronic disease & -1.029 & 6.110 & $\mathbf{0 . 0 1 3}$ & 0.357 & $0.158-0.808$ \\
\hline Birth complication & 0.793 & 9.979 & $\mathbf{0 . 0 0 2}$ & 2.209 & $1.351-3.612$ \\
\hline Extra learning & -0.343 & 2.510 & 0.113 & 0.710 & $0.464-1.085$ \\
\hline Family working & & & $\mathbf{0 . 0 0 3}$ & & \\
\hline One spouse work & 0.380 & 2.947 & 0.086 & 1.462 & $0.948-2.255$ \\
\hline Neither working & 1.463 & 11.069 & $\mathbf{0 . 0 0 1}$ & 4.320 & $1.824-10.230$ \\
\hline Mother education & 0.073 & 0.052 & 0.820 & 1.075 & $0.575-2.011$ \\
\hline Father education & 0.382 & 1.219 & 0.270 & 1.466 & $0.743-2.889$ \\
\hline
\end{tabular}

${ }^{\mathrm{a}}$ Binary logistic regression was performed, Adj OR: Adjusted odds ratio, CI: Confidence interval. 